\title{
Experimental Study on Bearing Capacity of Straight Welded Pipe Used in Transmission Towers with Weld Defect
}

\author{
Jianjun Liu* \\ Jiangsu Electric Power Company Research Institute, Nanjing, Jiangsu, China \\ ${ }^{*}$ Corresponding author
}

\begin{abstract}
A method for simulating welding defect of slags or incomplete fusion is raised in this research. Experiments on seven full-size members were conducted.The research shows that the length of the welding defect is related to the decrease of the ultimate bearing capacity of the members under the static axial load.In some case, it may be the main factor to reduce the bearing capacity, which mayeven be lower than the code limits so attention should be paid to engineering application.
\end{abstract}

Keywords-weld defects; straight welded pipe; experimental study; ultimate bearing capacity; buckling

\section{INTRODUCTION}

In recent years, Transmission towers with large diameter steel tubes as the main members of the structure are a new type of towers with great development potential, which are widely used in large span transmission lines. In these structures, large diameter straight welded pipes are in application because of simple and efficient production process. The defects in welded pipe is inevitable and may induce brittle fracture of welded structure.

Defects such as crack, air hole, slag inclusion, incomplete fusion and so on exist because of Influence of various factors in welding process. Different types of welding defects have different geometry, contour, gray distribution, location, extension direction and other characteristics. The bearing capacity of the members with welded defects are studied extensively. Binnur Goren Kiral, SecilErim(2006) studied the bending bearing capacity of beam column connections with incomplete fusion weld defects and put forward five solutions of node strengthening ${ }^{[5]}$. K.K.Tang etc.(2010) considered that the existence of initial defects can significantly reduce the structural stiffness. Local defects tend to affect the weldment details and structural rigidity more appreciably than changes in the structural nominal strains ${ }^{[6]}$. Long Z.Y, Zhang G(1995) evaluated the influence of welding defects on the structural strength. It is considered that welding defect is the main cause of stress concentration. The stress concentration factor of the welding defect tip is deduced by the theory of fracture mechanics ${ }^{[8]}$. Based on the practical engineering, the types of welding defects in the welded joints of the steel tube truss joints are summarized by Ren Zhisen(2004). He simulated typical surface or internal defects and obtained the influence curves of different types and sizes of defects in the ultimate bearing capacity of the joints of different welds and the different positions of the same weld ${ }^{[7]}$.
The mechanism of weld defects is complex, and the form is diverse. It has important influence on the mechanical properties of structures. In practical engineering, capacity reduction of steel pipe tower component containing weld defects is still difficult to quantify, so experiments on seven full-size members were conducted and the results were compared with the steel structure design code of China and the United States. The relationship between the bearing capacity of the steel tube member and the weld defect is defined.

\section{TEST DESIGN AND IMPLEMENTATION}

\section{A. Specimen Design}

The components are high frequency resistance welding seam welded pipes with diameter $168 \mathrm{~mm}$ and wall thickness $6 \mathrm{~mm}$, the full-scale diagonal members on transmission steel tower.The designed slenderness ratio are 40, 50, 60 and the radius-thickness ratio is 28.According to GB50017-2003 "steel structure design code" terms 5.4.5: when the radius-thickness ratio of circular section, the local instability will not happen.In the middle part of the pipe section, the high temperature resistant ceramic plates are used to simulate the welding slag or the incomplete fusion defect, and the plates are fixed on the groove of welding through the instant dry heat glue.The size of the ceramic plate is $10 \mathrm{~mm} \times 2 \mathrm{~mm} \times 1 \mathrm{~mm}$. The length of the radial weld defect is simulated by the combination of the ceramic plate along the length direction. Considering the uncertainties of the simulated length in the actual welding process, after the welding is finished, the length of the measured defect is obtained by ultrasonic nondestructive testing. Specimen design is shown in Figure I and Figure II.

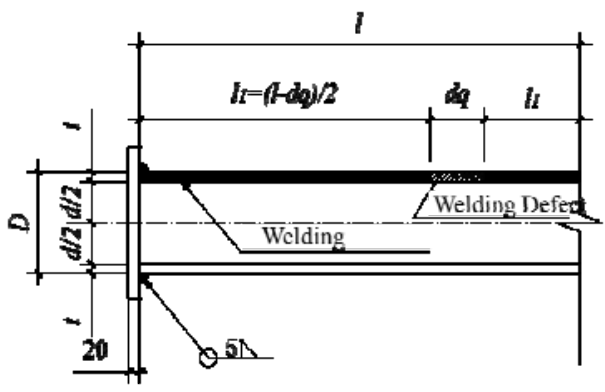

FIGURE I. SCHEMATIC DIAGRAM OF SPECIMEN DESIGN. 


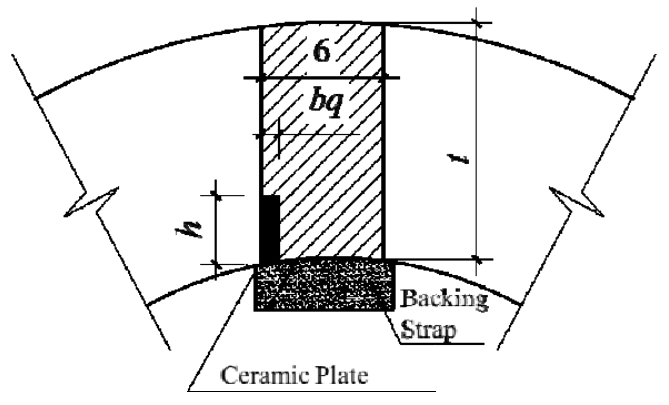

FIGURE II. DEFECT SIMULATION SECTION

\section{B. Experiment Plan}

$5000 \mathrm{kN}$ standard long column hydraulic test machine is used and the axial load is applied through the top hydraulic jack. In order to effectively simulate the constraint conditions of the two ends of the component and facilitate the installation of components, two-way blade hinges are installed in the both ends of the specimens. In the form of the combination of geometry and physics, the method avoids the eccentricity in the initial stage of loading.

The experiment objective is to obtain the ultimate load values of the specimens under axial compression. At the same time, in order to obtain the corresponding relationship between the stress and deformation in the weld defect position and other section, The $1 / 4,1 / 2$ and $3 / 4$ cross sections along the longitude direction of each specimen are arranged in a total of 12 strain measuring points, which contains 8 bidirectional strain measuring points. At the same time the location of weld defects in radial and lateral direction of 90 degrees and a total of 4 orthogonal arrangement of cable displacement meter. 4 wire type displacement meters are arranged in the location of weld defects in longitudinal, transverse and orthogonal directions. Experiment is implemented with a continuous load system, loading speed is $10 \mathrm{kN} / \mathrm{min}$. Reduce the speed at $60 \%$ ultimate load. In the case of the total failure of the specimens, the readings of the measuring points under the ultimate load are acquired.

\section{EXPERIMENTAL RESULTS}

The measured values of the ultimate bearing capacity of each member in this test are listed in table I and compared with the suggested design value in "Specification Structural Steel Buildings"AISC360-2010 in USA and the GB50017-2003 "steel structure design code" in China. Ultrasonic nondestructive testing is carried out before experiment. The testing results show that in the introduction of ceramic chip simulation weld slag or incomplete fusion defects, other types of defects may also be introduced in. It leads to the actual defect length greater than the length of the design defect. At the same time, the small diameter welded pipe manufacture quality is poor, the initial defect itself contains will also affect the ultimate bearing capacity. Through experiment comparison, in the case of the same slenderness ratio and the same diameter thickness ratio, the ultimate bearing capacity of the member is related to the length of the actually contained defect. The greater the length of the defect, the lower the ultimate load.
Because of the initial eccentricity and residual stress of the actual structure, at the same time, considering the welding process may be introduced in addition to the design defects of other types such as porosity, not welded thoroughly, etc., in this experiment, the ultimate bearing capacity of the specimens is not only related to the length of the defect, and the relationship is not linear.

The stress state and failure modes of each specimen in the test are nearly the same.The load-lateral displacement curves are shown in Figure III, IV, and V. The strain and displacement are linearly growing at the initial stage of loading.The growth speed of displacement is very slow. When the load reached the limit of $80 \%$ or so, the lateral deformation velocity of the specimens began to increase. Nonlinear growth appears in the load displacement curve, until the overall instability in the limit state.At this point the displacement is far beyond linear stage. When the ultimate load is reached, the specimen is buckling, and the specimen is beginning to unload.

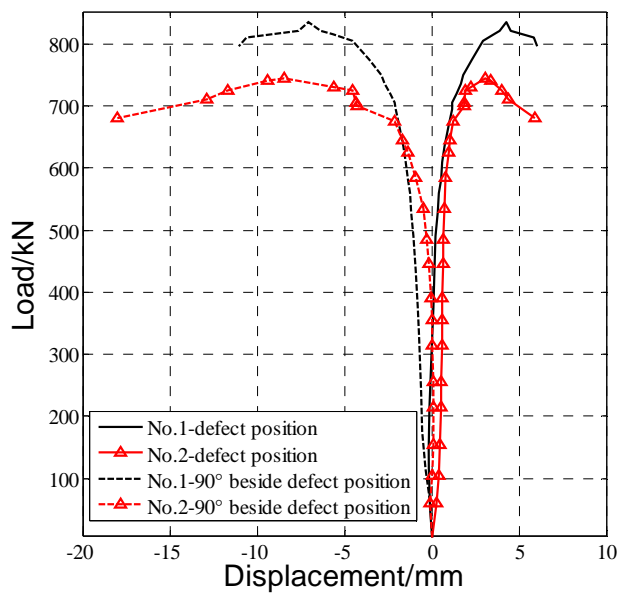

FIGURE III. LOAD-LATERAL DISPLACEMENT CURVES -GROUP 1

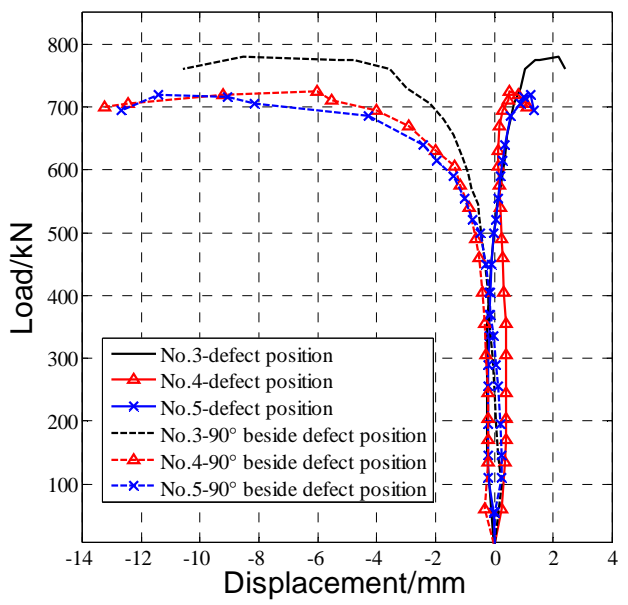

FIGURE IV. LOAD-LATERAL DISPLACEMENT CURVES -GROUP 2 


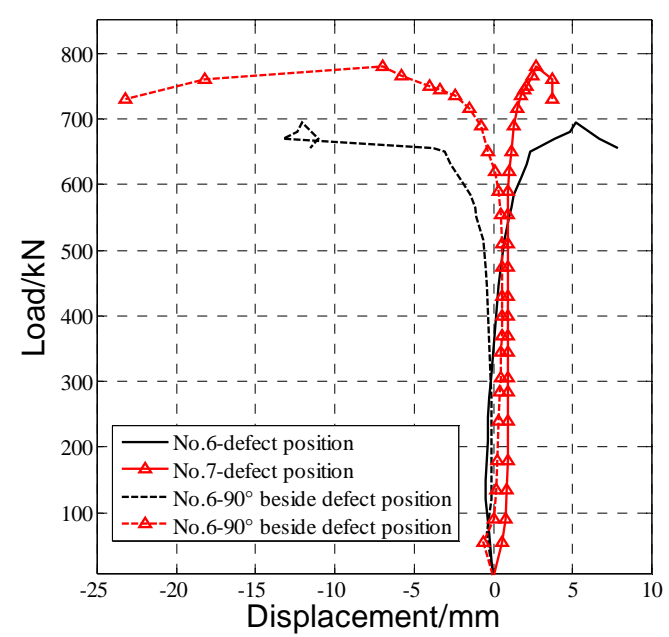

FIGURE V. LOAD-LATERAL DISPLACEMENT CURVES -GROUP 3.

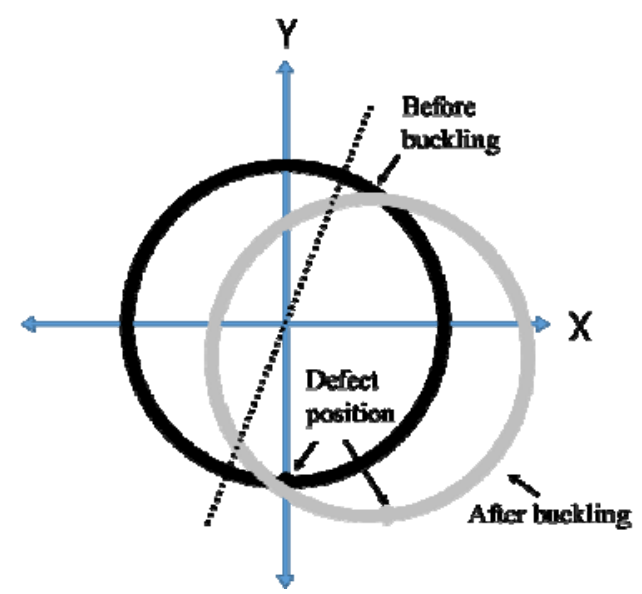

FIGURE VII. CROSS SECTION DEFORMATION DIAGRAM

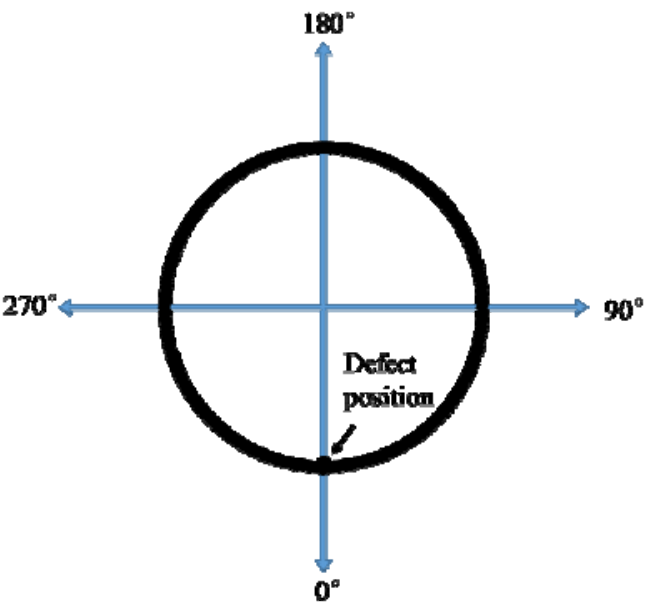

FIGURE VI. POSITION OF WELD DEFECT.

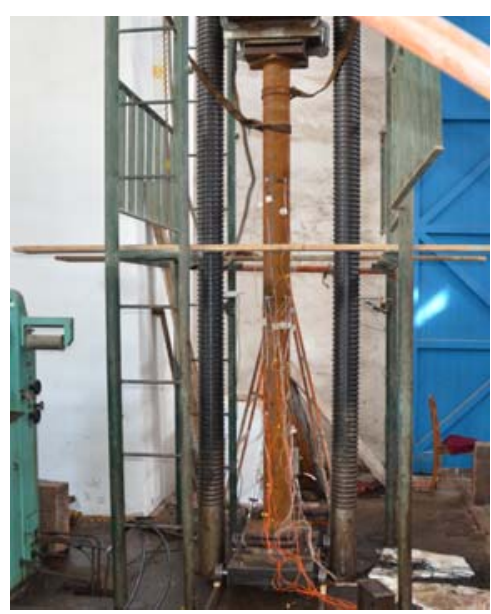

FIGURE VIII. SCHEMATIC DIAGRAM OF THE OVERALL INSTALLATION OF SPECIMENS.

TABLE I. THE RELATIONSHIP BETWEEN THE LENGTH OF THE WELD DEFECT AND THE ULTIMATE BEARING CAPACITY

\begin{tabular}{|c|c|c|c|c|c|c|c|}
\hline Group & No & $\begin{array}{l}\text { Designed Length } \\
\text { of Defect } / \mathrm{mm}\end{array}$ & $\begin{array}{l}\text { Detected Length } \\
\text { of Defect/mm }\end{array}$ & $\begin{array}{c}\text { Slenderness } \\
\text { Ratio }\end{array}$ & $\begin{array}{l}\text { Tested Ultimate } \\
\text { Load } / \mathrm{kN}\end{array}$ & $\begin{array}{c}\text { GB50017-2003 } \\
\text { Suggested value/kN }\end{array}$ & $\begin{array}{c}\text { AISC360-2010 } \\
\text { Suggested value /kN }\end{array}$ \\
\hline \multirow{2}{*}{1} & 1 & 50 & 65 & \multirow{2}{*}{40} & 825 & 872.2 & 789.0 \\
\hline & 2 & 100 & 92 & & 745 & 872.2 & 789.0 \\
\hline \multirow{3}{*}{2} & 3 & 0 & 0 & \multirow{3}{*}{50} & 780 & 812.6 & 730.8 \\
\hline & 4 & 50 & 64 & & 725 & 812.6 & 730.8 \\
\hline & 5 & 100 & 170 & & 720 & 812.6 & 730.8 \\
\hline \multirow{2}{*}{3} & 6 & 50 & 85 & \multirow{2}{*}{60} & 780 & 741.8 & 660.6 \\
\hline & 7 & 100 & 133 & & 695 & 741.8 & 660.6 \\
\hline
\end{tabular}

As shown in Table 1, when the specimens are in the stable lateral displacement at the defect position.Combined with the limit state, the bending degree of the cross section is more obvious, the load is continuously reduced and the strain gauge and displacement meter reading is increasing.In addition, figure VI and VII show when getting the ultimate load, the lateral displacement at the $90^{\circ}$ position is obviously higher than the experimental phenomenon, the whole instability of the symmetrical axis of the joint of the component is about 30 degrees.

Under the condition of static loading, the influence of the defect site on the bearing capacity is mainly reflected in the 
weakening of the section. As shown in Figure IX, at the same time taking into account the weld defect length and the length of the member, when the ratio is larger, the bearing capacity of the member is lower. When the ratio of defect length and specimen length is more than 0.025, the bearing capacity is increased. The reason is that on one hand the expansion of the area under the condition of static loading is difficult to appear, and the influence of the stability limit on the bearing capacity is limited in the area of the local area; On the other hand, the existence of weld defects causes the local geometry changes, resulting in the stress concentration and the inertia axis of the member cross section is also the factor of the instability of the component.

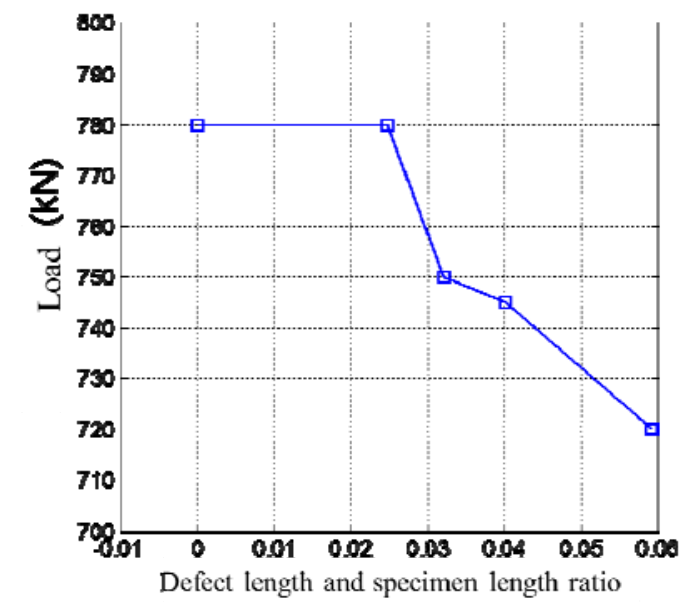

\section{FIGURE IX. EFFECT OF DEFECT LENGTH ON DIFFERENT LENGTH OF SPECIMENS}

\section{CONCLUSIONS}

In this study, a method for simulating welding defect of slags or incomplete fusion is raised and experiments on seven full-size members were conducted, the following conclusions are obtained.

1) In the case of the same slenderness ratio and the same diameter thickness ratio, the ultimate bearing capacity of the member is related to the length of the actually contained defect. The greater the length of the defect, the lower the ultimate load.

2) Simulation of weld defects is not the only reason for the reduction of the bearing capacity of the specimens. The initial defects in the actual specimens such as initial eccentricity and residual stress should also be considered. However, in the same condition of initial imperfections, the reduction of bearing capacity caused by the length of simulated weld defect is more prominent.

3) When getting the ultimate load, the lateral displacement at the $90^{\circ}$ position is obviously higher than the lateral displacement at the defect position.Combined with the experimental phenomenon, the whole instability of the symmetrical axis of the joint of the component is about 30 degrees.

4) Under the condition of static loading, the influence of the defect site on the bearing capacity is mainly reflected in the weakening of the section. At the same time taking into account the weld defect length and the length of the member, when the ratio is larger, the bearing capacity of the member is lower.

\section{REFERENCES}

[1] Jiao Fujie. Analysis of welding structure basis [M]. Shanghai: Shanghai science and Technology Literature Press, 1991

[2] GB 50017-2003. Steel structure design specification [S]. Beijing: China Planning Press, 2003

[3] AISC Committee. Specification for Structural Steel Buildings [J]. (36010 ANSI/AISC) American Institute of Steel Construction

[4] AISC Committee. Specification for Structural Steel Buildings (ANSI/AISC 360-10)[J]. American Institute of Steel Construction, Chicago-Illinois, 2010.

[5] Kiral B G, Erim S. Performance of Steel Beam-to-Column Connections with Weld Defects under Inelastic Cyclic Loading [J]. Advances in Structural Engineering, 2006, 9(4): 561-575.

[6] Tang K K, Li Z X, He D D, et al. Evolution of plastic damage in welded joint of steel truss with pre-existing defects [J]. Theoretical and Applied Fracture Mechanics, 2010, 54(2): 117-126.

[7] Ren Senzhi. Welding defects and the impact on the bearing capacity of steel tubular joints welded by [D].

[8] Long Zhanyun, Zhang Gang. The influence of defects on structural strength of welded [J]. Nondestructive testing, 1995 (3): 10-13. 